\title{
Highly prevalent TERT promoter mutations in aggressive thyroid cancers
}

\author{
Xiaoli Liu, Justin Bishop', Yuan Shan ${ }^{2}$, Sara Pai ${ }^{3}$, Dingxie Liu, Avaniyapuram \\ Kannan Murugan, Hui Sun ${ }^{4}$, Adel K El-Naggar ${ }^{5}$ and Mingzhao Xing
}

\begin{abstract}
Laboratory for Cellular and Molecular Thyroid Research, Division of Endocrinology and Metabolism, Johns Hopkins University School of Medicine, 1830 East Monument Street, Suite 333, Baltimore, Maryland 21287, USA 'Department of Pathology, Johns Hopkins University School of Medicine, Baltimore, Maryland 21287, USA ${ }^{2}$ Departments of Anatomic Pathology and Neuro-Oncology, Moffitt Cancer Center, Tampa, Florida 33612, USA ${ }^{3}$ Department of Otolaryngology-Head and Neck Surgery, Johns Hopkins University School of Medicine, Baltimore, Maryland 21287, USA

${ }^{4}$ Jilin Provincial Key Laboratory of Surgical Translational Medicine, Department of Thyroid and Parathyroid Surgery, China-Japan Union Hospital, Jilin University, Changchun, Jilin Province 130033, China

${ }^{5}$ Department of Pathology, University of Texas MD Anderson Cancer Center, Houston, Texas 77030, USA
\end{abstract}

Correspondence should be addressed to $M$ Xing Email mxing1@jhmi.edu

\begin{abstract}
Mutations $1295228 \mathrm{C}>$ T and $1295250 \mathrm{C}>$ T (termed C228T and C250T respectively), corresponding to $-124 \mathrm{C}>\mathrm{T}$ and $-146 \mathrm{C}>\mathrm{T}$ from the translation start site in the promoter of the telomerase reverse transcriptase (TERT) gene, have recently been reported in human cancers, but not in thyroid cancers yet. We explored these mutations in thyroid cancers by genomic sequencing of a large number of primary tumor samples. We found the C228T mutation in 0 of $85(0.0 \%)$ benign thyroid tumors, 30 of $257(11.7 \%)$ papillary thyroid cancers (PTC), 9 of $79(11.4 \%)$ follicular thyroid cancers (FTC), 3 of $8(37.5 \%)$ poorly differentiated thyroid cancers (PDTC), 23 of 54 (42.6\%) anaplastic thyroid cancers (ATC), and 8 of 12 (66.7\%) thyroid cancer cell lines. The C250T mutation was uncommon, but mutually exclusive with the C228T mutation, and the two mutations were collectively found in 11 of 79 (13.9\%) FTC, 25 of 54 (46.3\%) ATC, and 11 of 12 (91.7\%) thyroid cancer cell lines. Among PTC variants, the C228T mutation was found in 4 of 13 (30.8\%) tall-cell PTC (TCPTC), 23 of 187 (12.3\%) conventional PTC, and 2 of 56 (3.6\%) follicular variant PTC samples. No TERT mutation was found in 16 medullary thyroid cancer samples. The C228T mutation was associated with the BRAF V600E mutation in PTC, being present in 19 of 104 (18.3\%) BRAF mutation-positive PTC vs 11 of $153(7.2 \%)$ the $B R A F$ mutation-negative PTC samples $(P=0.0094)$. Conversely, $B R A F$ mutation was found in 19 of $30(63.3 \%)$ C228T mutation-positive PTC vs 85 of 227 (37.4\%) C228T mutation-negative PTC samples $(P=0.0094)$. We thus for the first time, to our knowledge, demonstrate TERT promoter mutations in thyroid cancers, that are particularly prevalent in the aggressive thyroid cancers TCPTC, PDTC, ATC and BRAF mutation-positive PTC, revealing a novel genetic background for thyroid cancers.
\end{abstract}

\section{Key Words}

- TERT promoter mutations

- thyroid cancers

- BRAF V600E mutation

- telomerase reverse transcriptase

- thyroid tumorigenesis http://erc.endocrinology-journals.org DOI: 10.1530/ERC-13-0210
(C) 2013 Society for Endocrinology Printed in Great Britain
Published by Bioscientifica Ltd.
Endocrine-Related Cancer (2013) 20, 603-610 


\section{Introduction}

Telomerase, a ribonucleoprotein complex that maintains telomere length at the end of chromosomes, plays a key role in cellular immortality and tumorigenesis (Smekalova et al. 2012, Mocellin et al. 2013). Its catalytic subunit is telomerase reverse transcriptase (TERT). Promoter mutations in the TERT gene on chromosome 5 have recently been reported in melanomas (Horn et al. 2013, Huang et al. 2013). Two TERT promoter mutations, $1295228 \mathrm{C}>\mathrm{T}$ and $1295250 \mathrm{C}>\mathrm{T}$ (termed C228T and C250T here respectively), are particularly common. They represent nucleotide changes of $-124 \mathrm{C}>\mathrm{T}$ and -146 $\mathrm{C}>\mathrm{T}$ (where -1 is the base just upstream of the $\mathrm{A}$ of the ATG translation start site) respectively in the TERT promoter. Both the mutations create an 11-base nucleotide stretch 5'-CCCCTTCCGGG-3', which contains a consensus binding site, GGAA (in reverse complement), for ETS transcription factors, suggesting potentially important biological relevance of these mutations. In fact, the two mutations have been demonstrated to confer increased transcriptional activity on the TERT promoter (Horn et al. 2013, Huang et al. 2013). These mutations are not found in normal human subjects and in the public genetic databases and are, therefore, cancerspecific somatic genetic alterations, further supporting their potentially important role in human tumorigenesis. This is consistent with the previously observed increased telomerase activities in some human cancers (Smekalova et al. 2012, Mocellin et al. 2013). Thus, TERT promoter mutations, by promoting the expression of the catalytic subunit of telomerase in response to ETS transcription factors, probably represent a novel mechanism by which telomerase plays an important role in human tumorigenesis. Melanomas and follicular cell-derived thyroid cancer share considerably similar genetic backgrounds; for example, they both harbor the BRAF V600E mutation with a high prevalence (Davies et al. 2002, Xing 2005a). We were, therefore, prompted to explore TERT promoter mutations in thyroid cancers in the present study.

Follicular cell-derived thyroid cancer is a common endocrine malignancy the incidence of which, similar to that of melanoma, has been rising rapidly globally in recent years (Jemal et al. 2011, Howlader et al. 2012). Follicular cell-derived thyroid cancer can be classified into several histological types (DeLellis et al. 2004), among which the most common types are papillary thyroid cancer (PTC) and follicular thyroid cancer (FTC), which account for $85-90 \%$ and $10-15 \%$ of all the thyroid cancers respectively (DeLellis et al. 2004, Jemal et al. 2011,
Howlader et al. 2012). PTC can be further classified into a few subtypes or variants, the most common of which include conventional PTC (CPTC), follicular variant PTC (FVPTC), and tall-cell PTC (TCPTC). Other subtypes of PTC, such as the columnar variant, are rare. Unlike the rare but rapidly aggressive undifferentiated anaplastic thyroid cancer (ATC; Smallridge et al. 2012), PTC and FTC are indolent differentiated thyroid cancers (DTCs). There is also poorly differentiated thyroid cancer (PDTC), which has aggressiveness between that of DTC and ATC. Parafollicular C-cell-derived medullary thyroid cancer (MTC) is uncommon. Benign thyroid tumors are far more common than thyroid cancers. Various genetic alterations have been identified in thyroid cancers, which, by aberrantly driving various signaling pathways, play a fundamental role in thyroid tumorigenesis (Xing 2013). In the present study, we examined TERT promoter mutations in various thyroid tumors to explore novel genetic alterations in thyroid tumorigenesis.

\section{Subjects and methods}

\section{Thyroid tumor tissues, cell lines, and DNA}

Genomic DNA was isolated from thyroid tumor tissues and cell lines using standard procedures of proteinase $\mathrm{K}$ digestion, phenol-chloroform extraction, and ethanol precipitation. Use of human thyroid tissues was based on Institutional Review Board-approved protocols and written patient consent was obtained where appropriate. The study included 85 benign thyroid tumors, 257 PTC (consisting of 187 CPTC, 56 FVPTC, 13 TCPTC, and 1 columnar PTC), 79 conventional FTC, 8 PDTC, 54 ATC, and 16 MTC samples. Thyroid cancer cell lines included TPC1, C643, Hth7, FTC133, OCUT-1, K1, FB1, BCPAP, SW1736, KAT18, Hth74, and WRO. Their thyroid tumor origins are given in Table 1.

\section{Identification of TERT promoter mutations}

Standard PCR was carried out for genetic sequencing to identify TERT promoter mutations. Briefly, a fragment of the TERT promoter was amplified by PCR on genomic DNA using primers $5^{\prime}$-AGTGGATTCGCGGGCACAGA-3' (sense) and 5'-CAGCGCTGCCTGAAACTC-3' (antisense). This resulted in a PCR product of $235 \mathrm{bp}$, containing the sites where mutations $\mathrm{C} 228 \mathrm{~T}$ and C250T occur in melanomas (Horn et al. 2013, Huang et al. 2013). About

Published by Bioscientifica Ltd. 


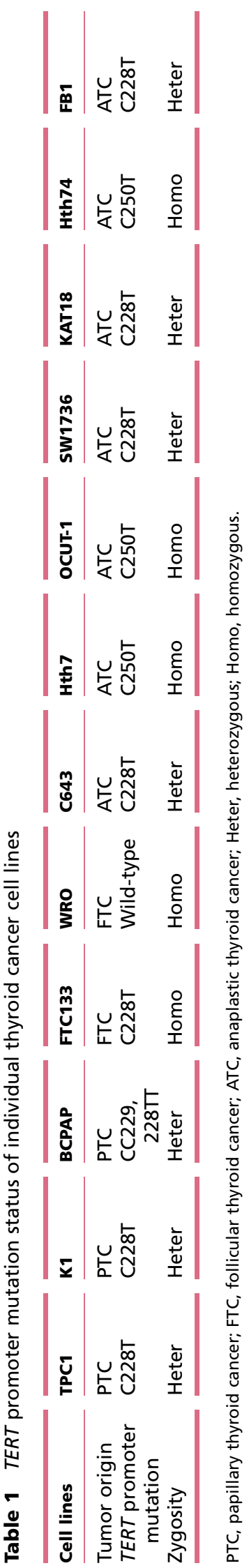

http://erc.endocrinology-journals.org DOI: 10.1530/ERC-13-0210
(C) 2013 Society for Endocrinology Printed in Great Britain
40-50 ng of genomic DNA were used in the PCR, which was carried out with an initial denaturation step at $95{ }^{\circ} \mathrm{C}$ for $3 \mathrm{~min}$, followed by ten cycles of $95^{\circ} \mathrm{C}$ denaturation for $30 \mathrm{~s}, 55^{\circ} \mathrm{C}$ annealing for $30 \mathrm{~s}$, and $68^{\circ} \mathrm{C}$ elongation for $1 \mathrm{~min}$. This was then followed by 30 cycles of the same settings except for elongation for an additional $5 \mathrm{~s}$ in each cycle. The PCR was completed with a final elongation step at $68{ }^{\circ} \mathrm{C}$ for $7 \mathrm{~min}$. Following quality confirmation of the PCR products by gel electrophoresis, sequencing PCR was carried out using a Big Dye terminator v3.1 cycle sequencing ready reaction kit (Applied Biosystems) and an ABI PRISM 3730 automated next generation genetic analyzer (Applied Biosystems) at the Johns Hopkins' sequencing facility. When a mutation was identified by Big Dye sequencing using the sense primer, the reaction was repeated using the antisense primer to confirm the mutation.

\section{Identification of BRAF V600E mutation}

The BRAF V600E mutation was analyzed as described previously (Hu et al. 2006). Briefly, exon 15 of the BRAF gene containing the site for the T1799A (V600E) mutation was PCR-amplified using primers TCATAATGCTTGCTCTGATAGGA (sense) and GGCCAAAAATTTAATCAGTGGA (antisense), resulting in a 212 bp product. The PCR settings included one cycle of $95^{\circ} \mathrm{C}$ for $5 \mathrm{~min}$; two cycles of $95{ }^{\circ} \mathrm{C}$ for $1 \mathrm{~min}, 60^{\circ} \mathrm{C}$ for $1 \mathrm{~min}$, and $72^{\circ} \mathrm{C}$ for $1 \mathrm{~min}$; two cycles of $95{ }^{\circ} \mathrm{C}$ for $1 \mathrm{~min}, 58^{\circ} \mathrm{C}$ for $1 \mathrm{~min}$, and $72^{\circ} \mathrm{C}$ for $1 \mathrm{~min}$; and 35 cycles of $95^{\circ} \mathrm{C}$ for $1 \mathrm{~min}, 56^{\circ} \mathrm{C}$ for $1 \mathrm{~min}$, and $72^{\circ} \mathrm{C}$ for $1 \mathrm{~min}$, followed by an extension step at $72{ }^{\circ} \mathrm{C}$ for $5 \mathrm{~min}$. After quality confirmation by agarose gel electrophoresis, the PCR products were subjected to Big Dye reaction and sequencing analysis as described above for TERT mutations. All the mutations were confirmed using both the sense and antisense primers.

\section{Results}

Prevalence of TERT promoter mutations in thyroid cancer cell lines and thyroid tumors

In Fig. 1, representative electropherograms of the two TERT promoter mutations in thyroid cancer cell lines and various primary thyroid cancer tumor samples detected by both sense (Fig. 1A) and antisense (Fig. 1B) primers are shown. In Table 1, the TERT promoter mutation status of the 12 individual thyroid cancer cell lines tested is summarized. Except for the WRO cell line that harbored the wild-type TERT promoter, all the remaining 11 thyroid

Published by Bioscientifica Ltd. 
A

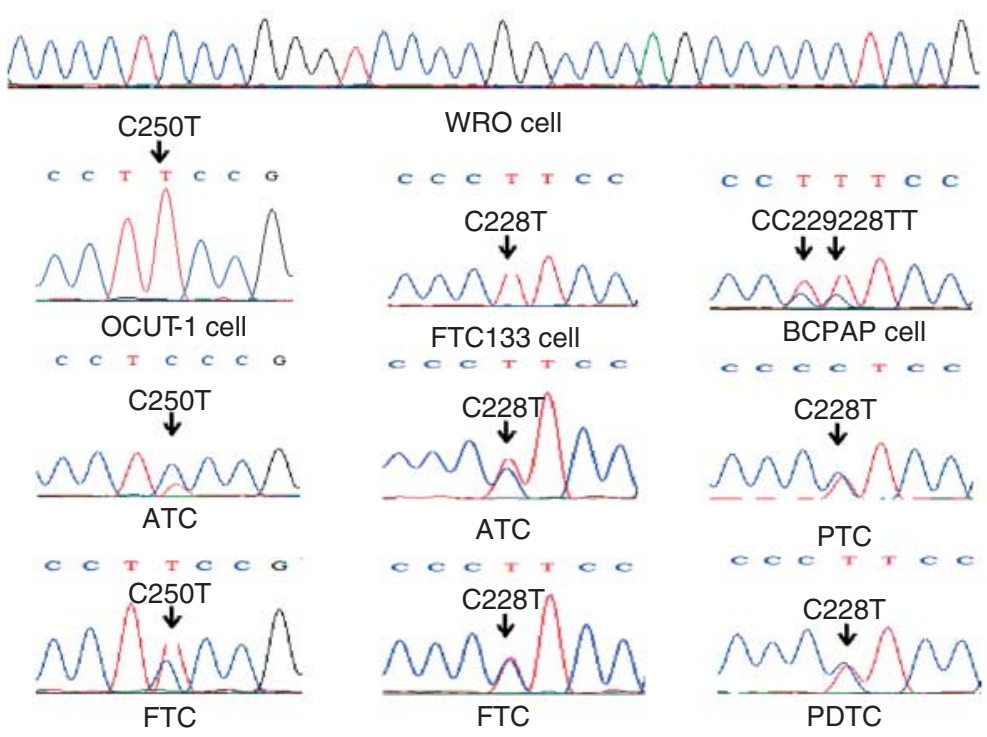

B
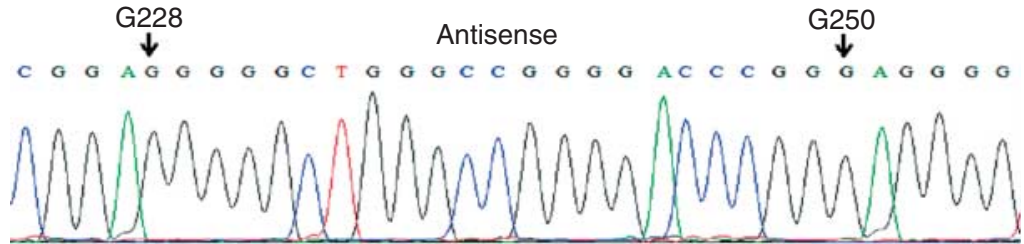

WRO cell

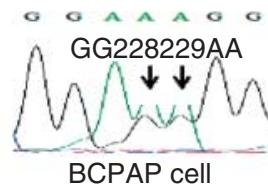

G G A A G O G
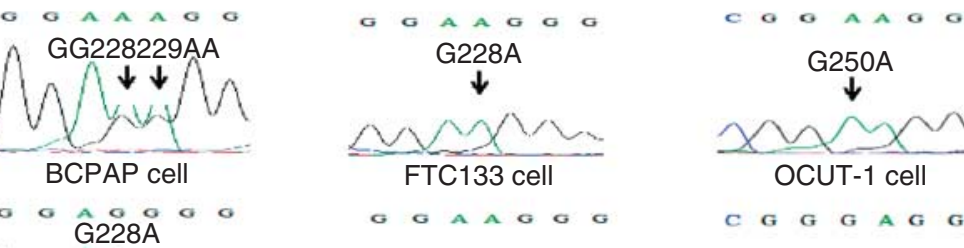

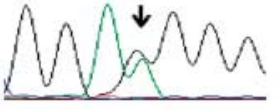

PTC

G G A G G G G G228A

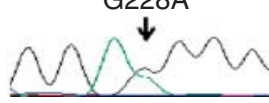

PDTC

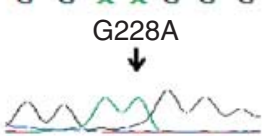

FTC133 cell
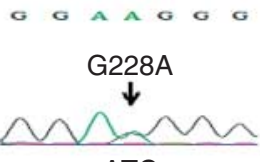

ATC
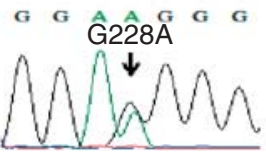

FTC

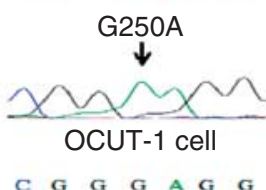

G A G G

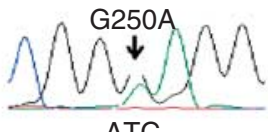

ATC

C G G A A G G

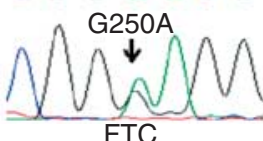

\section{Figure 1}

Sequencing of the human TERT promoter electropherograms. Representative electropherograms of the genomic DAN sequencing of the human TERT promoter for the two indicated mutations are shown. (A) The sense DNA strand obtained using the sense primer for sequencing, displaying TERT promoter mutations C228T and C250T in various thyroid cancer cell lines and thyroid cancer samples. (B) The antisense DNA strand obtained Printed in Great Britain using the antisense primer for sequencing, displaying TERT promoter mutations G228A and G250A in various thyroid cancer cell lines and thyroid cancer samples. (A and B) WRO cell line is used to show the wild-type human TERT promoter. PTC, papillary thyroid cancer; FTC, follicular thyroid cancer; ATC, anaplastic thyroid cancer; PDTC, poorly differentiated thyroid cancer.

Published by Bioscientifica Ltd. 
cancer cell lines examined harbored TERT promoter mutations. PTC and FTC cell lines only harbored the C228T mutation, while the ATC cell line harbored both the C228T and C250T mutations. Table 2 summarizes TERT promoter mutations found in all the thyroid cancer cell lines and primary thyroid tumors. The two mutations were collectively found in 11 of the 12 (91.7\%) thyroid cancer cell lines. The C228T mutation was found in 0 of $85(0.0 \%)$ benign thyroid tumor, 30 of 257 (11.7\%) PTC, 9 of 79 (11.4\%) FTC, 3 of 8 (37.5\%) PDTC, and 23 of 54 (42.6\%) ATC samples. Among the three variants of PTC, the C228T mutation was found in 4 of $13(30.8 \%)$ TCPTC, 23 of 187 (12.3\%) CPTC, and 2 of 56 (3.6\%) FVPTC samples. The single columnar PTC sample examined was positive for the $\mathrm{C} 228 \mathrm{~T}$ mutation. The $\mathrm{C} 250 \mathrm{~T}$ mutation was not found in the PTC sample, but was found in two FTC, two ATC, and three ATC cell lines. The two TERT promoter mutations were mutually exclusive in both thyroid cancer cell lines and thyroid cancer tumor samples and collectively found in 11 of 79 (13.9\%) FTC, 25 of 54 (46.3\%) ATC, and 7 of 7 (100\%) ATC cell lines. No TERT promoter mutation was found in 16 MTC samples. Three cases had both PTC and ATC in the same thyroid gland, and in each case, both the PTC and ATC harbored the C228T mutation. Three melanoma cell lines (M14, A375, and

Table 2 TERT promoter mutations in thyroid tumors

\begin{tabular}{|c|c|c|c|}
\hline Samples & $\begin{array}{l}\text { Mutation } \\
\text { C228T } \\
(n / N(\%))\end{array}$ & $\begin{array}{c}\text { Mutation } \\
\text { C250T } \\
(n / N(\%))\end{array}$ & $\begin{array}{c}\text { Collective } \\
\text { mutations } \\
(n / N(\%))\end{array}$ \\
\hline \multicolumn{4}{|c|}{ Thyroid cancer cell lines } \\
\hline PTC & $3 / 3(100.0)$ & $0 / 3(0.0)$ & 3/3 (100.0) \\
\hline FTC & $1 / 2(50.0)$ & $0 / 2(0.0)$ & $1 / 2(50.0)$ \\
\hline ATC & 4/7 (57.1) & $3 / 7(42.9)$ & 7/7 (100.0) \\
\hline All & $8 / 12(66.7)$ & 3/12 (25.0) & $11 / 12(91.7)$ \\
\hline \multicolumn{4}{|c|}{ Thyroid tumors } \\
\hline $\begin{array}{l}\text { Benign } \\
\text { tumor }\end{array}$ & $0 / 85(0.0)$ & $0 / 85(0.0)$ & $0 / 85(0.0)$ \\
\hline \multicolumn{4}{|l|}{ PTC } \\
\hline CPTC & 23/187 (12.3) & 0/187 (0.0) & 23/187 (12.3) \\
\hline FVPTC & $2 / 56(3.6)$ & $0 / 56(0.0)$ & 2/56 (3.6) \\
\hline TCPTC & 4/13 (30.8) & $0 / 13(0.0)$ & 4/13 (30.8) \\
\hline Columnar & 1/1 (100.0) & $0 / 1(0.0)$ & 1/1 (100.0) \\
\hline All & $30 / 257(11.7)$ & $0 / 257(0.0)$ & $30 / 257(11.7)$ \\
\hline FTC & 9/79 (11.4) & 2/79 (2.5) & 11/79 (13.9) \\
\hline DTC & 39/336 (11.6) & 2/336 (0.6) & $41 / 336(12.2)$ \\
\hline PDTC & $3 / 8(37.5)$ & $0 / 8(0.0)$ & $3 / 8(37.5)$ \\
\hline ATC & 23/54 (42.6) & 2/54 (3.7) & 25/54 (46.3) \\
\hline MTC & $0 / 16(0.0)$ & $0 / 16(0.0)$ & $0 / 16(0.0)$ \\
\hline
\end{tabular}

PTC, papillary thyroid cancer; CPTC, conventional PTC; FVPTC, follicular variant PTC; TCPTC, tall-cell PTC; FTC, follicular thyroid cancer; DTC, differentiated thyroid cancer (combination of PTC and FTC); PDTC, poorly DTC; ATC, anaplastic thyroid cancer; MTC, medullary thyroid cancer.
UACC62) examined harbored the C250T mutation (data not shown), as found in other melanoma cell lines (Horn et al. 2013, Huang et al. 2013). All the TERT mutations in the tumor samples were heterozygous, and some cell lines harbored a homozygous C228T or C250T mutation (Table 1). We also found a $\mathrm{C}>\mathrm{T}$ mutation at position chromosome 5: 1295 229, which is adjacent to the C228T mutation, resulting in a CC $>$ TT tandem mutation in the BCPAP cell line (Fig. 1A). This is similar to the occasional finding of this tandem mutation in melanomas (Horn et al. 2013, Huang et al. 2013). A germline $A>C$ ( $T>G$ on opposite strand) mutation at $-57 \mathrm{bp}$ from the ATG translation start site of the TERT gene was found in familial melanomas (Horn et al. 2013), but we did not find this mutation in any of the thyroid tumor samples or cell lines in the present study. We also did not find this mutation and other TERT promoter mutations in the peripheral blood DNA of 18 patients with familial PTC from a previous study (Xing 2005b).

\section{Association of TERT promoter mutations with aggressive types of thyroid cancers}

CPTC, FVPTC, and TCPTC account for the vast majority of PTC variants. TCPTC is classically known to be more aggressive than CPTC and FVPTC. As shown in Table 3, TERT promoter mutations were significantly more prevalent in the TCPTC samples than in the CPTC and FVPTC samples, $30.8 \%(4 / 13)$ in the former vs $10.3 \%$ $(25 / 243)$ in the latter two $(P=0.046$, per two-tailed Fisher's exact test). TERT promoter mutations were highly significantly more prevalent in the ATC samples than in the DTC samples, $46.3 \%(25 / 54)$ in the former vs $12.2 \%$ $(41 / 336)$ in the latter $\left(P=3 \times 10^{-8}\right)$. There was a trend towards a higher prevalence of TERT promoter mutations in the PDTC samples than in the DTC samples, $37.5 \%(3 / 8)$ in the former vs $12.2 \%(41 / 336)$ in the latter $(P=0.069)$. Statistical significance was not reached, probably due to the relatively small number of PDTC samples.

\section{Association of TERT promoter mutation C228T with BRAF V600E mutation in PTC}

BRAF V600E mutation, which activates the MAPK pathway, is the most common mutation in thyroid cancers, particularly in PTC (Xing 2005a). We, therefore, analyzed the relationship between this mutation and TERT promoter mutation C228T in PTC. As shown in Table 4, TERT promoter mutation C228T more commonly occurred in the PTC samples harboring the BRAF V600E

Published by Bioscientifica Ltd 
Table 3 Association of TERT promoter mutations with aggressive thyroid cancers

\begin{tabular}{|c|c|c|}
\hline $\begin{array}{l}\text { Types of thyroid } \\
\text { cancers }\end{array}$ & $\begin{array}{c}\text { Collective TERT } \\
\text { promoter mutations } \\
(n / N(\%))\end{array}$ & P value $^{a}$ \\
\hline TCРТC & 4/13 (30.8) & 0.046 \\
\hline CPTC+FVPTC & 25/243 (10.3) & \\
\hline ATC & $25 / 54(46.3)$ & $3 \times 10^{-8}$ \\
\hline DTC & $41 / 336$ (12.2) & \\
\hline PDTC & $3 / 8(37.5)$ & 0.069 \\
\hline DTC & $41 / 336(12.2)$ & \\
\hline
\end{tabular}

PTC, papillary thyroid cancer; TCPTC, tall-cell PTC; CPTC, conventional PTC; FVPTC, follicular variant PTC; DTC, differentiated thyroid cancer (combination of PTC and FTC); PDTC, poorly DTC; ATC, anaplastic thyroid cancer. aper two-tailed Fisher's exact test.

mutation than in the PTC samples harboring the wild-type $B R A F$ gene, with a prevalence of $18.3 \%(19 / 104)$ in the former vs $7.2 \%(11 / 153)$ in the latter $(P=0.0094$, per two-tailed Fisher's exact test). Conversely, BRAF mutation more commonly occurred in the PTC samples harboring the TERT promoter mutation than in the PTC samples harboring the wild-type TERT, 63.3\% (19/30) in the former vs $37.4 \%(85 / 227)$ in the latter $(P=0.0094)$. Thus, the majority of the TERT promoter mutation-positive PTC samples harbored the BRAF V600E mutation. Several cases of ATC had both BRAF V600E and TERT mutations, but the relationship of the two types of mutations could not be statistically analyzed in this cancer due to the small number of BRAF mutation-positive cases (Table 4).

\section{Discussion}

The recent discovery of TERT promoter mutations in melanomas is the first example, to our knowledge, indicating that mutations in gene promoters may also play an important oncogenic role (Horn et al. 2013, Huang et al. 2013). This represents a novel genetic mechanism in human tumorigenesis. A subsequent report of the existence of TERT promoter mutations in other human cancers (Killela et al. 2013) and our report on the high prevalence of these mutations in bladder cancer and glioblastoma (Liu etal.2013) suggest that TERT promoter mutations may play a huge role in human tumorigenesis. We report here for the first time, to our knowledge, that common TERT promoter mutations are also in observed thyroid cancer.

We found no TERT promoter mutations in parafollicular C-cell-derived MTC samples, consistent with similar findings in a recent study on 24 MTC samples (Killela et al. 2013). However, due to the relatively small number of samples examined, the status of TERT promoter mutations in MTC cannot be definitively concluded. In contrast, in the analysis of a large cohort of follicular cellderived thyroid cancer samples in the present study, we found a common occurrence of TERT promoter mutations in both PTC and FTC samples, suggesting a role of these mutations in the tumorigenesis of a subgroup of these DTCs. The lack of TERT promoter mutations in benign thyroid tumor samples suggests that these mutations are malignancy-specific and may be relatively late genetic events along the line of thyroid tumorigenesis. Consistent with this idea is the strikingly higher prevalence of TERT promoter mutations in PDTC and ATC than in DTCs; PDTC and ATC have partially and completely lost differentiation respectively and are the most aggressive thyroid cancers. This raises the possibility that TERT promoter mutations may play a particular role in the de-differentiation of DTCs and hence their conversion to poorly or undifferentiated aggressive thyroid cancers. This possibility is consistent with the finding in three cases in which co-existing PTC and ATC in the same thyroid gland harbored TERT promoter mutation C228T. The prevalence of TERT promoter mutations was extremely high in thyroid cancer cell lines $(91.7 \%)$, which is in contrast to the low prevalence of $16 \%(24 / 150)$ in general cancer cell lines from the Cancer Cell Line Encyclopedia (Huang et al. 2013), but is similar to the high prevalence of $74 \%$ $(125 / 168)$ in melanoma cell lines (Horn et al. 2013). This result is again consistent with the idea that TERT promoter mutations may play a role in the de-differentiation of thyroid cancer cells since thyroid cancer cell lines in

Table 4 Association of TERT promoter C228T mutation with BRAF V600E mutation in PTC

\begin{tabular}{|c|c|c|c|c|c|c|}
\hline \multirow[b]{2}{*}{ Tumor type } & \multicolumn{2}{|c|}{ TERT C228T mutation $(n / N(\%))$} & \multirow[b]{2}{*}{$\boldsymbol{P}_{\text {value }}{ }^{a}$} & \multicolumn{2}{|c|}{ BRAF V600E mutation $(n / N(\%))$} & \multirow[b]{2}{*}{ P value $^{a}$} \\
\hline & $\mathrm{BRAF}-$ & $\mathrm{BRAF}+$ & & TERT - & TERT + & \\
\hline PTC & $11 / 153(7.2)$ & $19 / 104(18.3)$ & 0.0094 & $85 / 227(37.4)$ & $19 / 30(63.3)$ & 0.0094 \\
\hline ATC & $20 / 44(45.5)$ & $5 / 10(50.0)$ & 1.0 & $5 / 29(17.2)$ & $5 / 25(20.0)$ & 1.0 \\
\hline
\end{tabular}

PTC, papillary thyroid cancer; ATC, anaplastic thyroid cancer.

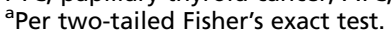

http://erc.endocrinology-journals.org DOI: 10.1530/ERC-13-0210
(C) 2013 Society for Endocrinology Printed in Great Britain
Published by Bioscientifica Ltd. 
culture commonly become de-differentiated (van Staveren et al. 2007). Interestingly, among the three common variants of PTC, TCPTC harbored TERT promoter mutations with the highest prevalence. TCPTC is a relatively uncommon but more aggressive PTC variant than CPTC and FVPTC (Xing et al. 2005, Ghossein et al. 2007, LiVolsi 2010). It is possible that TERT promoter mutations play a role in the aggressiveness of this unique PTC variant. This is again consistent with the idea that TERT promoter mutations may play a role in the development of progression and aggressiveness of thyroid cancers.

As in many other human cancers in which telomerase activities are increased (Smekalova et al. 2012, Mocellin et al. 2013), increased telomerase activities have also been found in thyroid cancers but not in normal thyroid tissues or benign thyroid tumors, suggesting a role of this enzyme in thyroid cancer tumorigenesis (Capezzone et al. 2009). Both TERT promoter C228T and C250T mutations create binding sites for ETS transcription factors, which subsequently promote the expression of TERT (Horn et al. 2013, Huang et al. 2013). Thus, TERT promoter mutations may contribute to thyroid tumorigenesis by aberrantly promoting the expression of TERT. Interestingly, some ETS factors are targets of the MAPK signaling pathway (Janknecht et al. 1995, Whitmarsh et al. 1995, Strahl et al. 1996). The MAPK pathway aberrantly activated by BRAF V600E plays a fundamental role in the tumorigenesis and progression of PTC (Xing 2013). It is thus possible that TERT promoter mutations may join the mechanisms involving the MAPK signaling in thyroid tumorigenesis. Consistent with this hypothesis is the particularly high prevalence of TERT promoter mutations in BRAF V600E mutation-positive PTC and vice versa found in the present study. The preferential occurrence of TERT promoter mutations in BRAF V600E mutation-positive PTC is also consistent with the hypothesis discussed above that these TERT promoter mutations may play a role in the aggressiveness of thyroid cancers since BRAF V600E mutation-positive PTC is more aggressive than PTC with wild-type BRAF (Xing et al. 2005, 2013a). The association between TERT promoter and BRAF V600E mutations creates a unique mechanism for the amplification of TERT expression, in which TERT promoter mutations create binding sites for ETS transcription factors, which, upon activation by BRAF V600E-promoted MAPK signaling, initiate or augment the expression of TERT. Thus, the co-existence of TERT promoter and BRAF V600E mutations conceivably confers thyroid cancers with a unique survival advantage. New treatments targeting molecular targets, such as BRAF V600E, are being actively sought and tested for thyroid cancers (Xing et al. 2013b). The finding of TERT promoter mutations in thyroid cancers opens an exciting possibility for the development of novel therapeutic agents targeting TERT in thyroid cancer patients. Given the association of TERT promoter mutations with BRAF V600E mutation and their presumed interaction through enhancement of the function of ETS transcription factors in regulating the expression of TERT, this therapeutic strategy may be particularly effective in patients with both TERT promoter mutations and BRAF V600E mutation.

In summary, herein, we report for the first time, to our knowledge, common TERT promoter mutations in thyroid cancers, which are particularly prevalent in aggressive types of thyroid cancers and in BRAF V600E mutationpositive PTC. Their occurrence patterns in various types of thyroid cancers suggest that these TERT promoter mutations may play a role in the de-differentiation, progression, and aggressiveness of thyroid cancers. The discovery of this novel genetic background of thyroid cancers opens exciting new opportunities for biological and clinical research of thyroid cancers.

\section{Declaration of interest}

$M$ Xing received royalties as a co-holder of a licensed USA patent related to the discovery and clinical characterization of BRAF V600E mutation in thyroid cancers.

\section{Funding}

This study was supported by NIH RO1-CA134225 grant to M Xing. We thank Dr Kimberly Studeman for providing thyroid tumor tissue samples used in our previous studies, and their leftover DNA samples were partially used in the present study. We thank Drs N E Heldin, K B Ain, N Onoda, M Santoro, D Wynford-Thomas, G Brabant, A P Dackiw, K Ain, G J Juillard, M Vitale, R E Schweppe, and B R Haugen for kindly providing us with- and facilitating the accessibility to the cell lines used in this study.

\section{References}

Capezzone M, Marchisotta S, Cantara S \& Pacini F 2009 Telomeres and thyroid cancer. Current Genomics 10 526-533. (doi:10.2174/ 138920209789503897)

Davies H, Bignell GR, Cox C, Stephens P, Edkins S, Clegg S, Teague J, Woffendin H, Garnett MJ, Bottomley W et al. 2002 Mutations of the BRAF gene in human cancer. Nature 417 949-954. (doi:10.1038/ nature00766)

DeLellis RA, Lloyd R, Heitz PU, Eng C (Eds) 2004 WHO Classification of Tumors, Pathology and Genetics-Tumors of Endocrine Organs. Lyon, France: IARC Press.

Ghossein RA, Leboeuf R, Patel KN, Rivera M, Katabi N, Carlson DL, Tallini G, Shaha A, Singh B \& Tuttle RM 2007 Tall cell variant of papillary thyroid carcinoma without extrathyroid extension: biologic

Published by Bioscientifica Ltd. 
behavior and clinical implications. Thyroid 17 655-661. (doi:10.1089/ thy.2007.0061)

Horn S, Figl A, Rachakonda PS, Fischer C, Sucker A, Gast A, Kadel S, Moll I, Nagore E, Hemminki K et al. 2013 TERT promoter mutations in familial and sporadic melanoma. Science 339 959-961. (doi:10.1126/science. 1230062)

Howlader N, Noone AM, Krapcho M, Neyman N, Aminou R, Altekruse SF, Kosary CL, Ruhl J, Tatalovich Z, Cho H et al. (eds) 2012 SEER Cancer Statistics Review, 1975-2009 (Vintage 2009 Populations). Bethesda, MD: National Cancer Institute (http://seer.cancer.gov/csr/ 1975_2009_pops09/, based on November 2011 SEER data submission, posted to the SEER web site, April 2012).

Hu S, Liu D, Tufano RP, Carson KA, Rosenbaum E, Cohen Y, Holt EH, Kiseljak-Vassiliades K, Rhoden KJ, Tolaney S et al. 2006 Association of aberrant methylation of tumor suppressor genes with tumor aggressiveness and BRAF mutation in papillary thyroid cancer. International Journal of Cancer 119 2322-2329. (doi:10.1002/ijc.22110)

Huang FW, Hodis E, Xu MJ, Kryukov GV, Chin L \& Garraway LA 2013 Highly recurrent TERT promoter mutations in human melanoma. Science 339 957-959. (doi:10.1126/science.1229259)

Janknecht R, Ernst WH \& Nordheim A 1995 SAP1a is a nuclear target of signaling cascades involving ERKs. Oncogene 10 1209-1216.

Jemal A, Bray F, Center MM, Ferlay J, Ward E \& Forman D 2011 Global cancer statistics. CA: A Cancer Journal for Clinicians 61 69-90. (doi:10.3322/caac.20107)

Killela PJ, Reitman ZJ, Jiao Y, Bettegowda C, Agrawal N, Diaz LA Jr, Friedman AH, Friedman H, Gallia GL, Giovanella BC et al. 2013 TERT promoter mutations occur frequently in gliomas and a subset of tumors derived from cells with low rates of self-renewal. PNAS 110 6021-6026. (doi:10.1073/pnas.1303607110)

Liu X, Wu G, Shan Y, Hartmann C, von Deimling A \& Xing M 2013 Highly prevalent TERT promoter mutations in bladder cancer and glioblastoma. Cell Cycle 12 1637-1638. (doi:10.4161/cc.24662)

LiVolsi VA 2010 Papillary carcinoma tall cell variant (TCV): a review. Endocrine Pathology 21 12-15. (doi:10.1007/s12022-010-9106-y)

Mocellin S, Pooley KA \& Nitti D 2013 Telomerase and the search for the end of cancer. Trends in Molecular Medicine 19 125-133. (doi:10.1016/ j.molmed.2012.11.006)

Smallridge RC, Ain KB, Asa SL, Bible KC, Brierley JD, Burman KD, Kebebew E, Lee NY, Nikiforov YE, Rosenthal MS et al. 2012 American Thyroid
Association Anaplastic Thyroid Cancer Guidelines Taskforce. American Thyroid Association guidelines for management of patients with anaplastic thyroid cancer. Thyroid 22 1104-1139. (doi:10.1089/thy. 2012.0302)

Smekalova EM, Shubernetskaya OS, Zvereva MI, Gromenko EV, Rubtsova MP \& Dontsova OA 2012 Telomerase RNA biosynthesis and processing. Biochemistry 77 1120-1128. (doi:10.1134/S000629 7912100045)

van Staveren WC, Solís DW, Delys L, Duprez L, Andry G, Franc B, Thomas G, Libert F, Dumont JE, Detours V et al. 2007 Human thyroid tumor cell lines derived from different tumor types present a common dedifferentiated phenotype. Cancer Research 67 8113-8120. (doi:10.1158/00085472.CAN-06-4026)

Strahl T, Gille H \& Shaw PE 1996 Selective response of ternary complex factor Sap1a to different mitogen-activated protein kinase subgroups. PNAS 93 11563-11568. (doi:10.1073/pnas.93.21.11563)

Whitmarsh AJ, Shore P, Sharrocks AD \& Davis RJ 1995 Integration of MAP kinase signal transduction pathways at the serum response element. Science 269 403-407. (doi:10.1126/science.7618106)

Xing M 2005a BRAF mutation in thyroid cancer. Endocrine-Related Cancer 12 245-262. (doi:10.1677/erc.1.0978)

Xing M $2005 b$ The T1799A BRAF mutation is not a germline mutation in familial nonmedullary thyroid cancer. Clinical Endocrinology 63 263-266. (doi:10.1111/j.1365-2265.2005.02332.x)

Xing M 2013 Molecular pathogenesis and mechanisms of thyroid cancer. Nature Reviews. Cancer 13 184-199. (doi:10.1038/nrc3431)

Xing M, Westra WH, Tufano RP, Cohen Y, Rosenbaum E, Rhoden KJ, Carson KA, Vasko V, Larin A, Tallini G et al. 2005 BRAF mutation predicts a poorer clinical prognosis for papillary thyroid cancer. Journal of Clinical Endocrinology and Metabolism 90 6373-6379. (doi:10.1210/jc.2005-0987)

Xing M, Alzahrani AS, Carson KA, Viola D, Elisei R, Bendlova B, Yip L, Mian C, Vianello F, Tuttle RM et al. 2013a Association between BRAF V600E mutation and mortality in patients with papillary thyroid cancer. Journal of the American Medical Association 309 1493-1501. (doi:10.1001/jama.2013.3190)

Xing M, Haugen BR \& Schlumberger M 2013 $b$ Promises in molecular-based management of differentiated thyroid cancer. Lancet 381 1058-1069. (doi:10.1016/S0140-6736(13)60109-9)

Received in final form 8 June 2013

Accepted 11 June 2013

Made available online as an Accepted Preprint

13 June 2013 http://erc.endocrinology-journals.org DOI: 10.1530/ERC-13-0210
(C) 2013 Society for Endocrinology Printed in Great Britain
Published by Bioscientifica Ltd. 